\title{
Memória e escola: olhares sensíveis para um patrimônio cultural
}

\author{
Maria Sílvia Duarte Hadler* \\ Maria Elena Bernardes**
}

\begin{abstract}
Resumo
Este artigo desenvolve reflexões em torno de relações entre memória, patrimônio cultural, sensibilidades e educação a partir da experiência de um projeto de extensão desenvolvido pelo Centro de Memória-Unicamp junto a uma escola pública municipal de Campinas, SP, entre 2014 e 2015. Atividades em conjunto com professores, a pesquisa em documentação da escola, bem como entrevistas com participantes atuais e anteriores da comunidade escolar, finalizando com a organização de uma exposição fotográfica, constituíram etapas fundamentais da realização deste projeto. Essa exposição fotográfica reuniu imagens de cenas cotidianas que se referiam a momentos significativos da história da escola. Fios de memórias desfiadas apontaram para a existência de um patrimônio cultural, em constante formação, com a potencialidade de ressignificar os sentidos atribuídos à trajetória da escola por vários de seus participantes, com a potencialidade de construção de identidades e de fortalecimento de relações de pertencimento. Um patrimônio que abriga possibilidades outras de atuação educacional.

Palavras-chave: Memórias; Patrimônio Cultural; Educação; Sensibilidades.
\end{abstract}

\section{Memory and school: sensitive looks for a cultural heritage}

\begin{abstract}
This article develops reflections on the relations between memory, cultural heritage, sensitivities and education from the experience of an extension project developed by the Centro de Memória (Memory Center) at Unicamp (State University of Campinas) with a public school in Campinas, SP, between 2014 and 2015. Activities in conjunction with teachers, the research into school documentation as well as interviews with participants of the school community, culminating with the organization of a photographic exhibition were key steps in implementing this project. This photo exhibition brought together images of everyday scenes, which referred to significant moments in the school's history. Memory threads pointed to the existence of a cultural heritage in constant formation, with the potentiality for reframing the meanings attributed to the school trajectory by several of his participants, the potentiality for building identities and strengthening the relationships of belonging. A heritage that comprises other possibilities of educational actions.
\end{abstract}

Keywords: Memories; Cultural Heritage; Education; Sensitivities.

\section{Introdução}

Na sociedade contemporânea vivemos sob o impulso dos ritmos acelerados dos tempos urbanos, atravessados pelas marcas da impessoalidade, das práticas individualistas, dos comportamentos muitas vezes automatizados. Cada vez mais assistimos ao escoamento dos tempos mais lentos necessários à reflexão, aos intercâmbios interpessoais (BENJAMIN, 1985). Esses traços socioculturais da modernidade contemporânea, associados às vivências em espaços sociais segmentados, submetidos a uma lógica hierárquica de valorizações/desvalorizações, nos enredam em sensações de desenraizamentos, de não pertencimento (SENNETT, 1997).

Dada a centralidade do urbano na contemporaneidade, tais traços socioculturais permeiam as variadas instâncias sociais e os diferentes espaços da cidade (MONGIN, 2009). Estão presentes nas dinâmicas culturais que constituem as relações sociais nesses espaços; tanto nos locais de trabalho, nos espaços de lazer e entretenimento, como também nas escolas.

Em que pese serem lugares, por excelência, de desenvolvimento de práticas educacionais diversas, as escolas também expressam essas dinâmicas socioculturais que predominam na sociedade contemporânea. No entanto, é preciso ressaltar que as escolas - sejam elas públicas ou privadas -, não são espaços homogêneos. Constituem-se, fundamentalmente, como espaços cheios de ambiguidades, tensões, contradições entre visões de mundo distintas, diferentes percepções e leituras dos processos educacionais, diferentes formas de sensibilidades expressas pelos diversos

\footnotetext{
*Endereço Eletrônico: masilvia@unicamp.br

** Endereço eletrônico: mebmaria@gmail.com
} 
sujeitos que circulam cotidianamente por estes espaços (GALZERANI, 2007).

Importante destacar, também, no que se refere a escolas públicas brasileiras, estaduais ou municipais, as tendências culturais, de perfil homogeneizador, presentes na sociedade brasileira, de desvalorização e desqualificação do trabalho docente nessas instituições. Tais tendências tendem a apagar e relegar ao esquecimento a atuação inovadora de professores que buscam construir possibilidades de práticas educacionais transformadoras, apesar das condições desfavoráveis de trabalho em que se encontram. Para além dos conteúdos escolares, e também na relação com eles, buscam trabalhar outras formas de produção de conhecimento na escola, que implicam o desenvolvimento de uma educação das sensibilidades que se coloque na contramão daquelas tendências culturais prevalecentes a que nos referimos anteriormente.

É em meio a esta trama de relações que foi desenvolvida a montagem de uma exposição fotográfica "Fragmentos de uma história - a EMEF Prof ${ }^{a}$. Dulce Bento Nascimento", inaugurada em novembro de 2015 na própria escola, localizada no bairro do Guará, distrito de Barão Geraldo, no município de Campinas, SP. Essa exposição reuniu imagens de cenas cotidianas e de momentos que marcaram a história da Escola Dulce Bento Nascimento, carinhosamente conhecida como Escola do Guará. Foi concebida no âmbito do projeto de extensão "Memória e Escola: ações educativas a partir do acervo do Centro de Memória-Unicamp", uma parceria entre o CMU e a escola $^{1}$.

A realização da exposição como um dos desdobramentos do projeto de extensão desenvolvido pelo Centro de Memória-Unicamp nos instiga a pensar sobre as potencialidades das relações que podem se estabelecer entre Universidade (no caso, a Unicamp) e a comunidade do entorno (no caso, uma escola pública municipal); por outro lado, nos estimula também a uma reflexão em torno da temática das múltiplas relações entre memória, patrimônio cultural e sensibilidades.

\section{Contextualizando o processo}

O projeto de extensão desenvolvido teve como propósito geral pensar os lugares de memória não como instituições passivas e depositárias do passado, onde circulam apenas pesquisadores e acadêmicos, mas, sim, como locais mediadores para a reconstituição da memória e da identidade. Um dos objetivos da aproximação entre o Centro de Memória-Unicamp e a escola Prof ${ }^{a}$. Dulce Bento Nascimento, por meio desse projeto, foi o de sensibilizar a comunidade escolar para a importância da memória e de sua preservação, visando trabalhar na formação de algumas condições para se implementar um possível Centro de Memória dessa escola. Para tanto, foram propostas ações conjuntas entre os professores, os pesquisadores e os técnicos do CMU, intercambiando informações e saberes relativos à preservação da memória e, também, tendo como horizonte, o intuito de explorar possibilidades de pesquisas e ações educativas a partir do acervo histórico do CMU.

A EMEF Prof ${ }^{\mathrm{a}}$. Dulce Bento Nascimento abrange bairros que mesclam características de zona rural e zona urbana, o que faz com que a comunidade escolar possua uma configuração bastante diversificada do ponto de vista social, econômico e cultural, e é composta por alunos oriundos de famílias que trabalham na prestação de serviços, comércio e lavoura na região. Situa-se num bairro de classe média e recebe poucos alunos que ali residem; boa parte vem de bairros mais distantes e há um grande número de alunos moradores de sítios e de loteamentos existentes em bairros de formação recente nessa região.

Foram observadas algumas dificuldades relativas ao trabalho conjunto com os professores. Devido a horários engessados, havia pouco tempo disponível para atividades relativas ao projeto. A organização dos tempos escolares não pouco favorece troca de experiências, discussões, estudos. Entretanto, apesar das dificuldades, um grupo de professores se mobilizou intensamente para a concretização dessa parceria.

Foram promovidas visitas dos professores da escola ao CMU para um contato com seu acervo e suas possibilidades de pesquisa e de utilização de documentos históricos para atividades em sala de aula.

Os professores participaram de oficinas de processamento técnico, conservação e restauro e de discussões acerca do papel fundamental da história oral na reconstituição da memória.

Ao longo dos anos foi produzida uma documentação variada na escola, relativa ao trabalho pedagógico cotidiano desenvolvido com os alunos, às atividades de gestão administrativa, aos eventos culturais que envolviam a comunidade. Esta documentação - fotografias, vídeos, trabalhos de 
alunos, livros-atas, registros de visitas de inspetores escolares, postagens no blog da escola, ofícios de demandas junto à Secretaria da Educação, textos jornalísticos da mídia oficial - necessita de tratamento e guarda adequados. Nesse sentido, a realização das oficinas técnicas que visaram a instrumentalização para a organização de arquivos, para a conservação e preservação de acervos constituiu um passo importante no processo de sensibilização para a formação de um futuro Centro de Memória da escola.

Por meio das discussões e reflexões conjuntas realizadas durante os encontros programados com a equipe participante do projeto, foi priorizada, primeiramente, a organização do conjunto de fotografias e seu processo de conservação e restauro. Ao mesmo tempo, foram realizadas pesquisas nos arquivos da Escola no intuito de coletar informações sobre os tempos iniciais de sua existência. Entrevistas com diversos sujeitos da comunidade escolar, tanto participantes atuais quanto anteriores, possibilitaram uma visão mais ampliada e enriquecedora de diversos momentos da trajetória escolar. Ao longo desse processo de trabalho conjunto tomou corpo, portanto, a ideia de realização de uma exposição com fotografias que, ao mostrarem o registro de cenas cotidianas, apontassem para momentos significativos da história da escola.

Dessa forma, o desenvolvimento do Projeto propiciou os passos iniciais para a formação do futuro Centro de Memória da escola, bem como para a montagem de uma exposição maior, pretendida por um grupo de professores, a ser realizada em 2018, quando a escola irá completar 40 anos.

No contexto da realização dessa parceria com a escola Prof ${ }^{a}$. Dulce Bento Nascimento nos deparamos com diversas questões significativas relativas às relações entre memória, arquivos, patrimônio e educação, sobre as quais julgamos oportuno tecer algumas considerações mais adiante.

\section{Imagens de uma história escolar}

A exposição fotográfica Fragmentos de uma História ${ }^{2}$ nos revela fragmentos do passado da história da escola. Fragmentos de histórias diversas que se desenrolaram e desenrolam naquele espaço escolar. Organizada em módulos temáticos, possibilita uma espécie de narrativa de momentos significativos da cultura escolar que veio se constituindo ao longo dos anos. Cenas diversas, dispersas no tempo. E o que nos contam estas imagens? Que costuras narrativas elas nos sugerem?

As primeiras imagens se referem aos tempos iniciais da escola que, inaugurada em 1978, funcionava em dois períodos apenas, com classes de $1^{a}$ a $3^{\text {a }}$ séries do Ensino Fundamental 1. Cenas da festa de encerramento e da primeira formatura da quarta série em 1979, deixando entrever o chão de terra batida da área externa, constituem momentos simbólicos importantes de concretização de uma trajetória educacional que se iniciou com inúmeras dificuldades.

Figura 1. Festa de encerramento do ano letivo no pátio da escola, Campinas, SP, 1979.

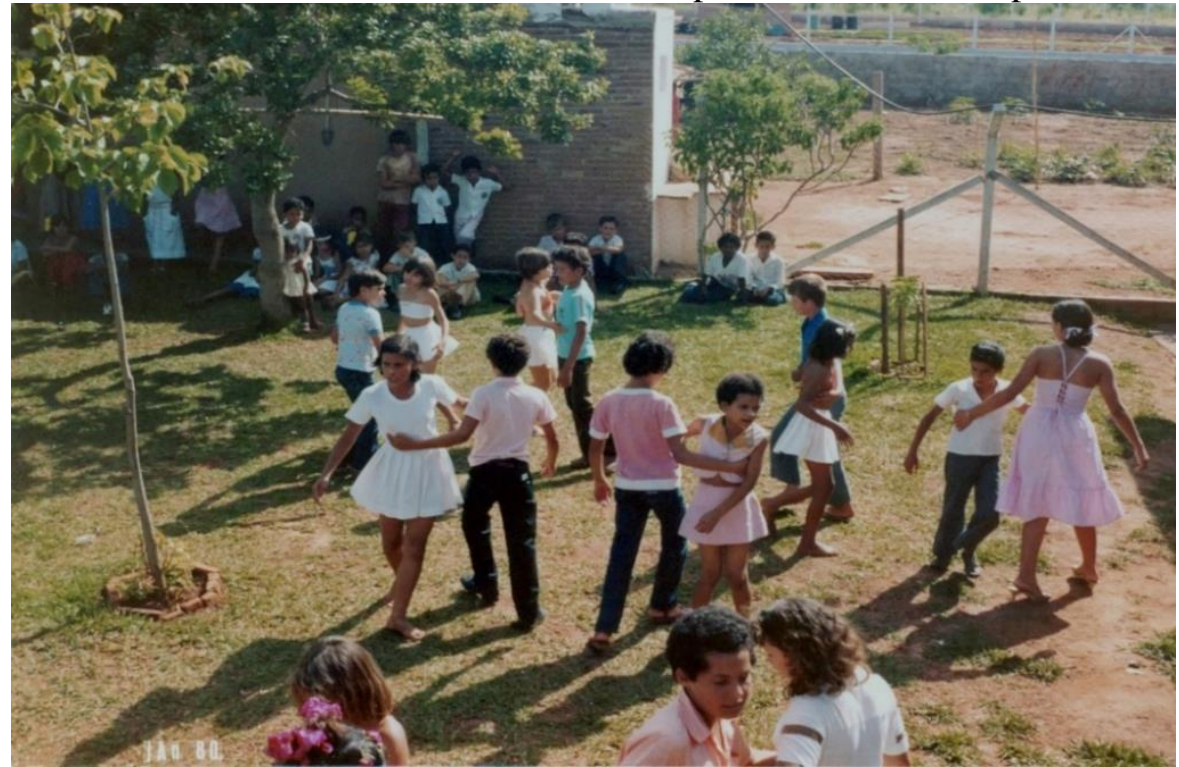

Fonte: Acervo da escola Dulce Bento Nascimento 
Figura 2. Construção das salas onde funcionou a pré escola, Campinas, SP, 1985.

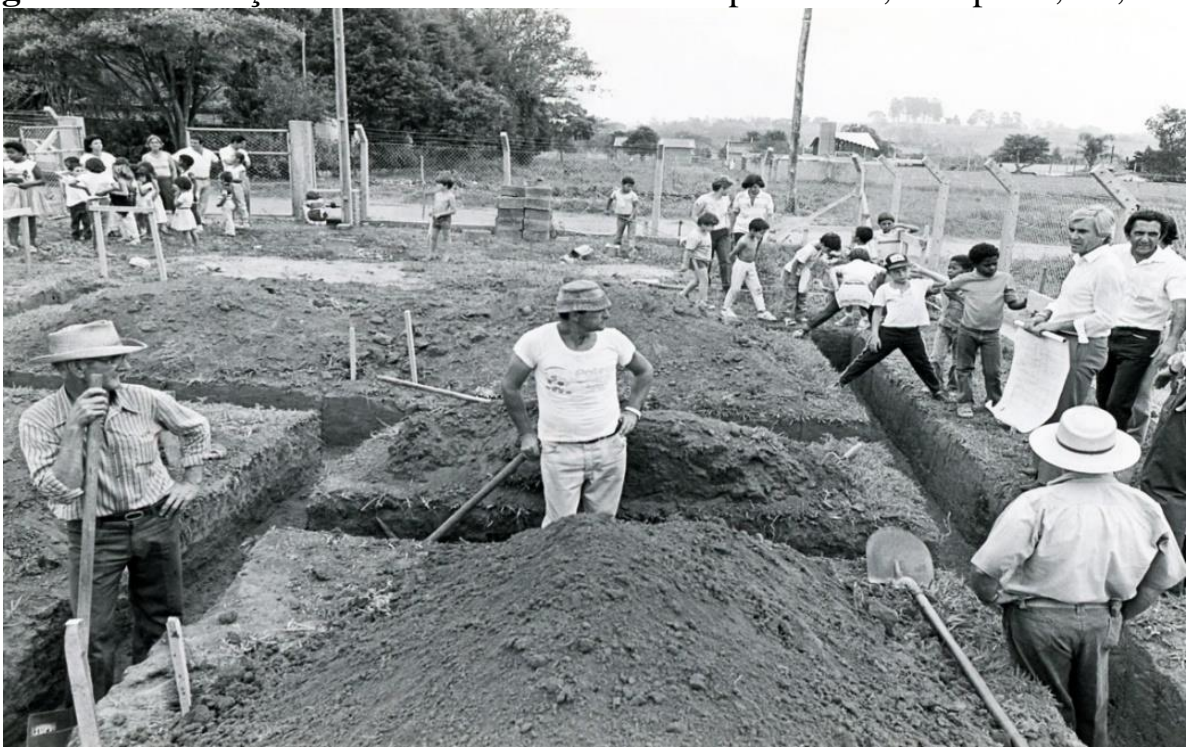

Fonte: Acervo da escola Dulce Bento Nascimento

Ao lado de imagens da construção de mais salas para abrigar a pré-escola em 1985 e do plantio de árvores pelos alunos, temos cenas que remetem tanto às diversas modificações e reestruturações do espaço escolar quanto ao cuidado com este espaço educacional coletivo que contou, sobretudo, com a colaboração efetiva de inúmeros pais e professores para que a escola pudesse se equipar melhor. A imagem de um grafite moderno estampado em toda uma parede de parte da fachada mais atual do prédio escolar - agora bastante ampliado - expressa a passagem do tempo e a atualização da escola frente a formas de expressão cultural mais recentes.

Figura 3. Parte da fachada da escola, onde se encontra atualmente a sala de vídeo, Campinas, SP.

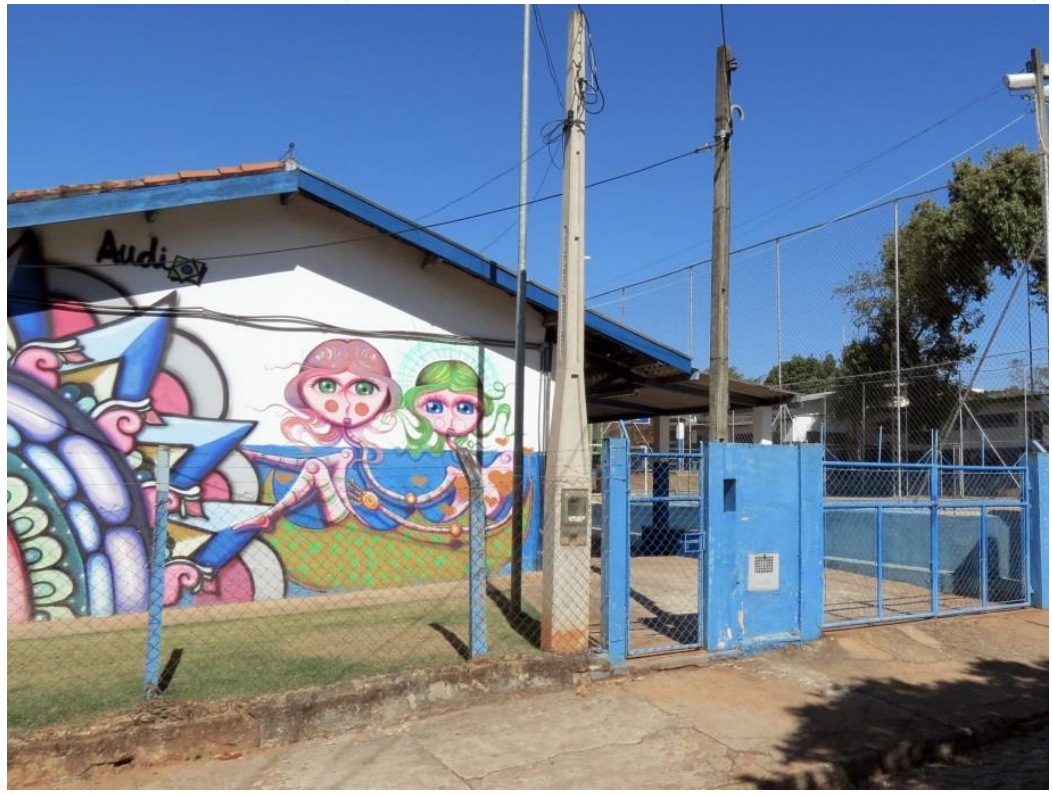

Fonte: Acervo da escola Dulce Bento Nascimento

Cenas de sala de aula nos indicam que, na história dessa escola, não houve uma única maneira de organização das salas e de realização das aulas: há situações de alunos enfileirados, ou organizados em pequenos grupos ou formando círculos maiores para propiciar prováveis discussões coletivas. Há indícios, portanto, de que os alunos foram instigados a ser protagonistas de seu processo de ensino e aprendizagem em diversos momentos. Atividades lúdicas, brincadeiras coletivas, gincanas, 
torneios esportivos, tanto nos Dias do Lazer dos primeiros anos da Escola, como em tempos atuais, têm, também, feito parte do currículo escolar, sinalizando um aspecto de permanência nessa trajetória educacional: os estudantes aprendem brincando, experimentam formas de convivência, de cooperação, de resolução de conflitos nas atividades extraclasse de que participam.

Figura 4. Corrida de sapatos (brincadeira Estafeta) dos alunos do $6^{\circ}$ ao $9^{\circ}$ ano realizada durante a Gincana, Campinas, SP, 2015.

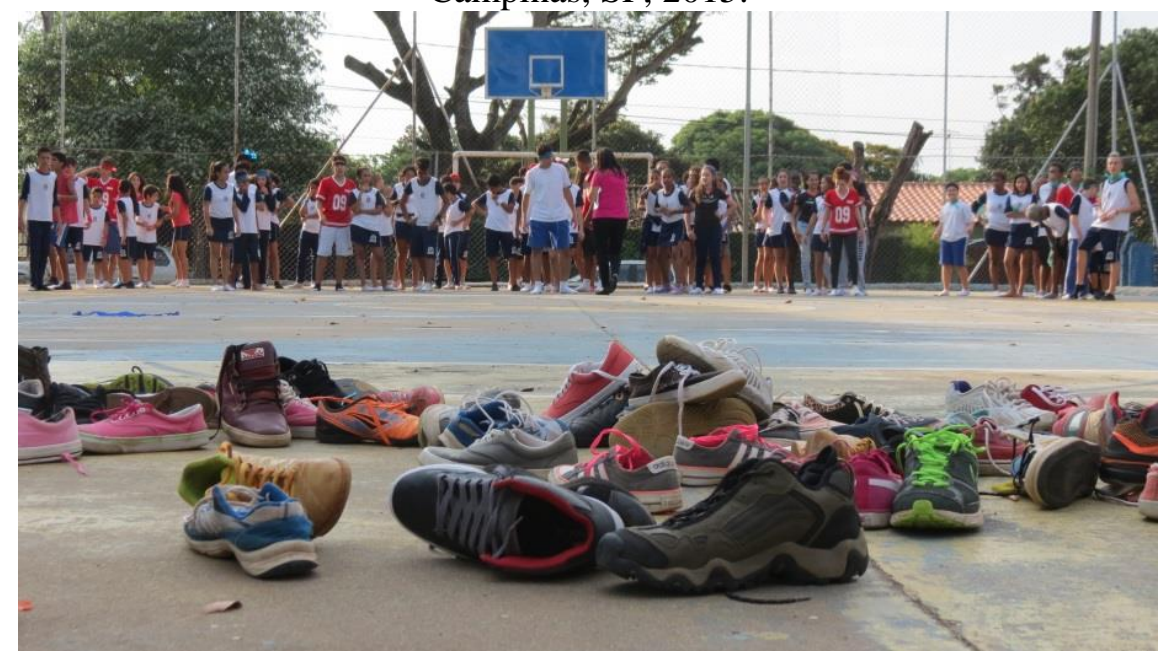

Fonte: Acervo da escola Dulce Bento Nascimento

Observa-se que as atividades pedagógicas não se restringiram à sala de aula. O aprendizado também se deu em diferentes espaços da cidade por meio de propostas de estudo de diversos professores. E na relação com grupos artísticos que se dispuseram a interagir com a escola, muitos alunos tiveram a possibilidade de ampliar seu horizonte de percepção do mundo em que vivem.
Dessa forma, o currículo escolar, ao longo dos anos, ao lado dos conteúdos tradicionalmente previstos, tem sido constituído por temas ligados à cultura, a diversas festas populares, tanto de abrangência nacional quanto local, como o caso da festa do Boi Falô, manifestação cultural popular peculiar ao distrito de Barão Geraldo, onde se localiza a escola,

Figura 5. Educadoras da ONG Gira Sonhos, Campinas, SP, 1998-1999.

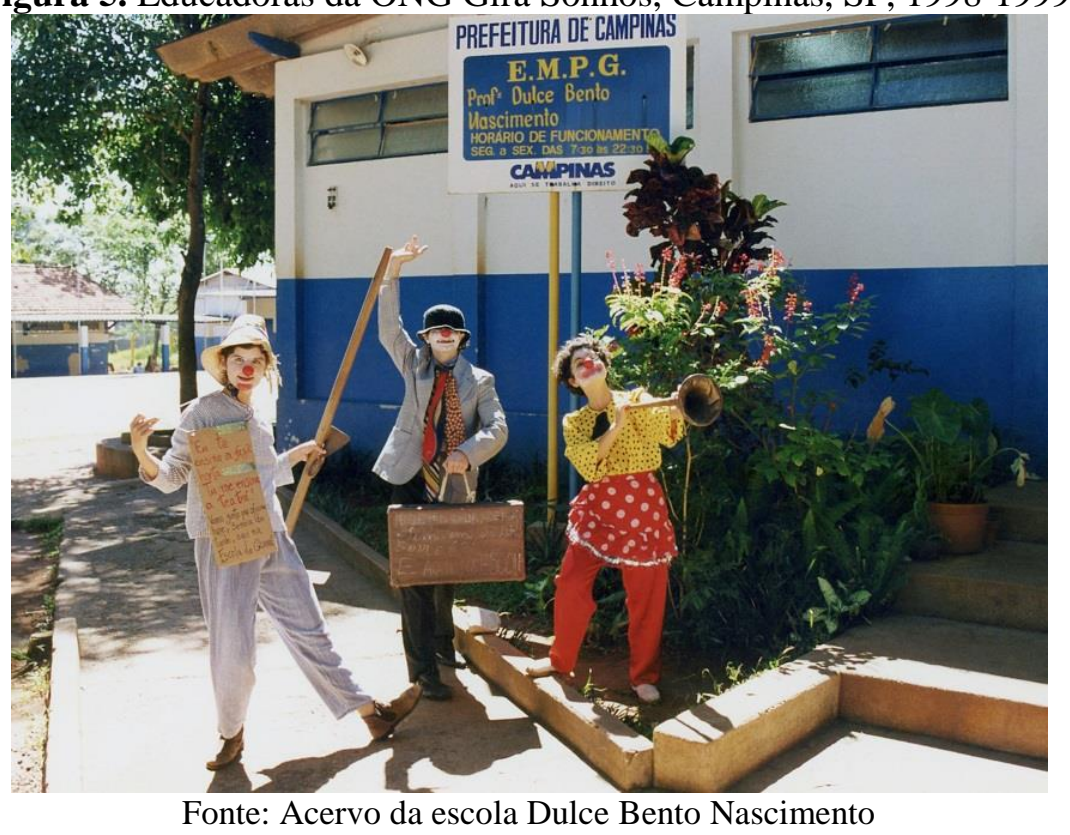


Figura 6. Apresentação relacionada ao Boi Falô, expressão da cultura popular em Barão Geraldo, Campinas, SP.

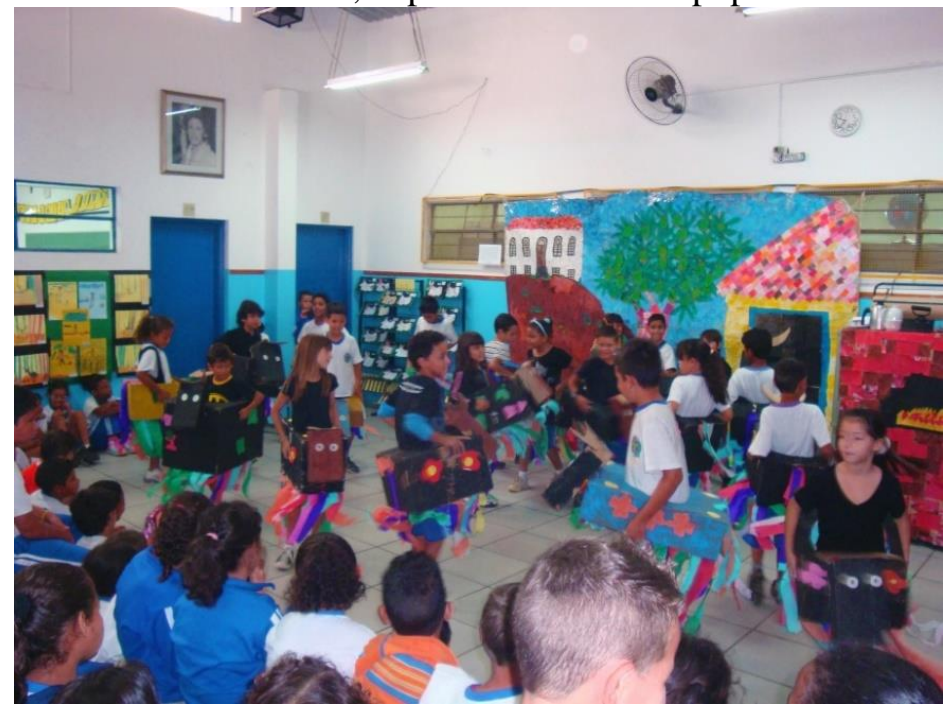

Fonte: Acervo da escola Dulce Bento Nascimento

Em algumas imagens da exposição podem ser captados indícios de estímulos à responsabilidade com o espaço coletivo e com o interesse coletivo, como por ocasião da existência de uma horta cuidada pelos alunos da antiga quarta série primária ou de situações de pintura da sala de aula em que professores participam conjuntamente dos trabalhos.

Há algumas evidências da presença de discussões sobre a atualidade e sobre questões relativas a preconceitos e discriminações, como a lousa preenchida por críticas ao episódio do índio queimado em Brasília.

Figura 7. Manifestação de alunos após discussão a respeito de discriminações e violência contra a população indígena no Brasil, Campinas, SP, década de 2000.

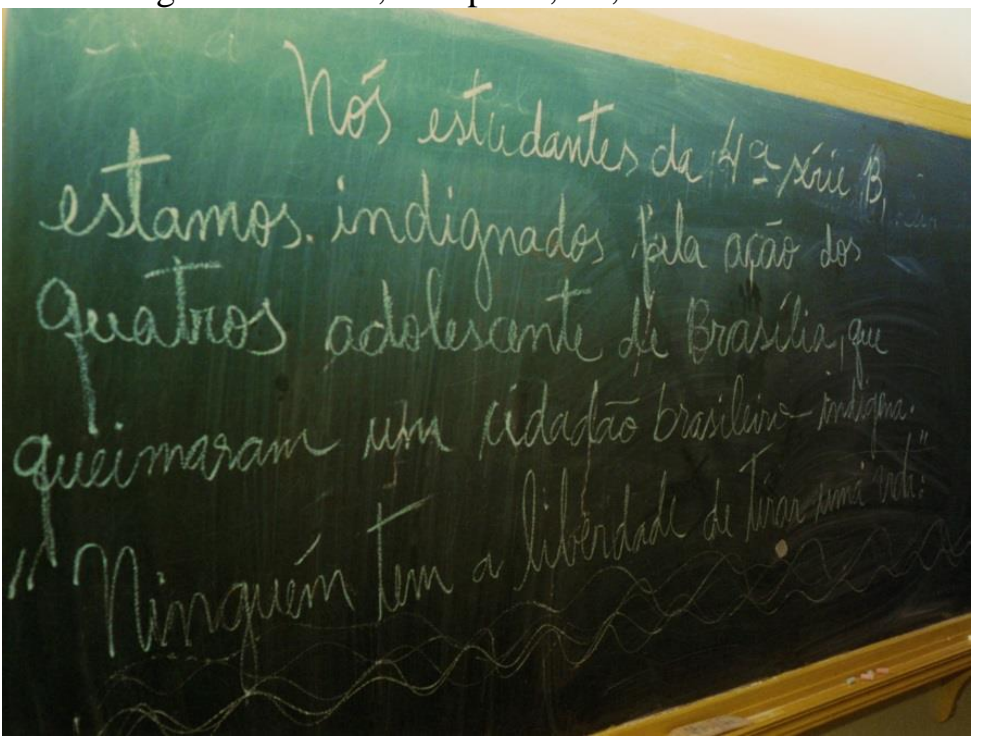

Fonte: Acervo da escola Dulce Bento Nascimento

Algumas imagens sinalizam o acompanhamento das inovações tecnológicas, desde o retro projetor, passando pelo vídeo e chegando aos computadores. As fotos corroboram informações de professores a respeito da introdução da informática na escola e da realização de diversas atividades dos alunos com o uso de recursos tecnológicos a partir de 2004. Houve parcerias com grupos da Universidade, como o Laboratório de Novas Tecnologias Aplicadas à Educação (Lantec), da Faculdade de Educação da Unicamp que, em convênio com o Centro de Pesquisa e 
Desenvolvimento em Telecomunicações (CPqD) introduziram novas tecnologias na escola, pesquisando possibilidades de utilização da TV digital interativa em sala de aula. Nessa ocasião, foram produzidos mais de 50 vídeos pelos alunos, tendo sido realizado em dezembro de 2005 um festival de curtas, em que 15 vídeos realizados pelos alunos possuíam a escola como tema.

Figura 8. Assistindo a um vídeo, Campinas, SP, década 2000.

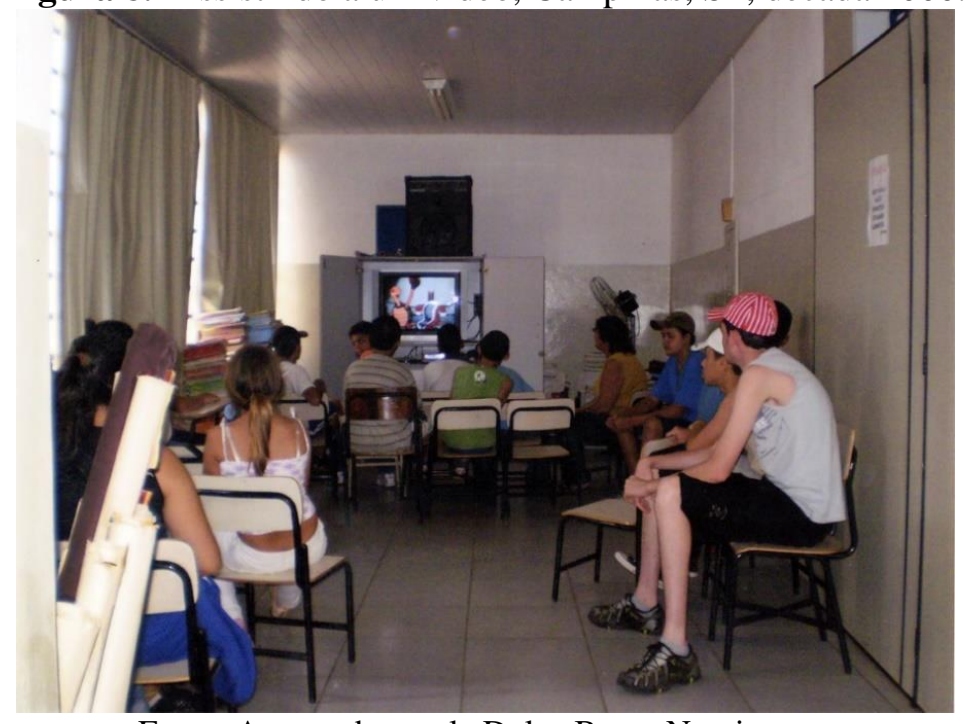

Fonte: Acervo da escola Dulce Bento Nascimento

Situações de ensino e aprendizagem como essas evocadas pelas fotografias expostas, apesar das descontinuidades de muitas dessas experiências, problematizam e questionam concepções desqualificadoras da escola pública e de seus professores, as quais circulam largamente por diversas instâncias da sociedade brasileira.

A escola contou, principalmente em seus anos iniciais, com forte colaboração das famílias dos alunos, de moradores do bairro no qual se localiza e também de funcionários e professores da própria escola. Fotografias da biblioteca em seus momentos iniciais e, posteriormente, mais ampliada, aludem a colaborações e doações para a sua formação, principalmente por parte do físico da Unicamp, Cesar Lattes e de sua família. O professor Lattes, que possuía uma chácara nas imediações da escola, realizou inúmeras contribuições, visitando regularmente suas dependências nos anos iniciais, e oferecendo ajuda para o desenvolvimento do ensino de ciências.

Figura 9. Biblioteca Carolina Maroni Lattes nos anos iniciais da escola, Campinas, SP.

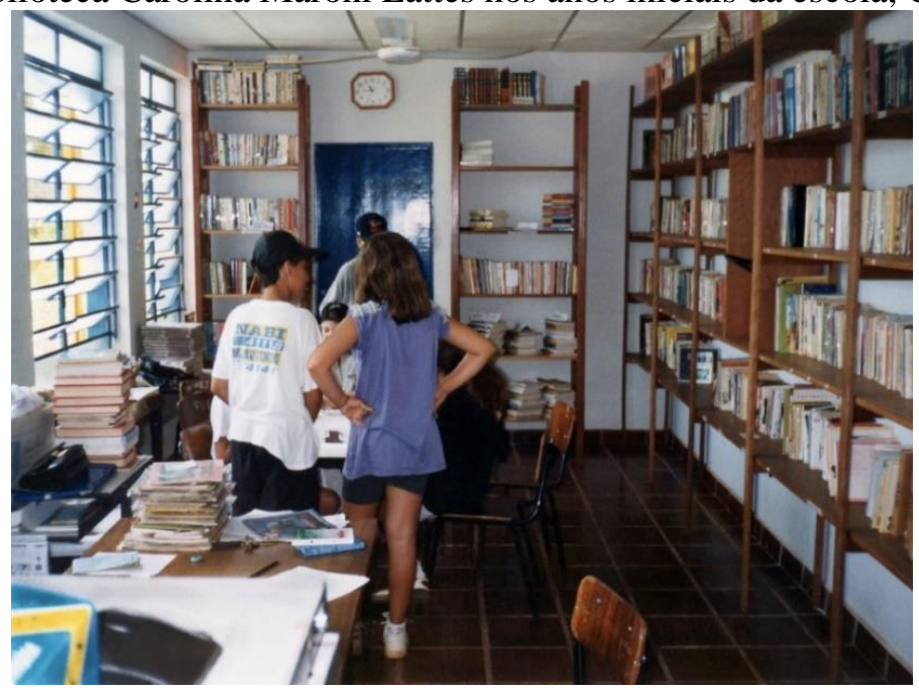

Fonte: Acervo da escola Dulce Bento Nascimento 
As imagens revelam, aos poucos, a dimensão política contida na cultura escolar, cujas movimentações, atravessadas por tensões, contradições e contraposições, constituem-se em experiências formativas para os diferentes sujeitos participantes da comunidade escolar. Essas imagens convidam-nos a perceber a dimensão política seja do gesto da discussão coletiva, do cuidado com o ambiente, do trabalho cooperativo, seja das eleições do grêmio estudantil e das manifestações dos professores por melhores condições de trabalho e contra as ameaças de privatização da gestão da educação pública municipal.

Estamos diante de uma visão fragmentária da história escolar, repleta de lacunas que podem ser preenchidas parcialmente por relatos de diversos sujeitos que participaram ou participam ainda dessa trajetória. As imagens fotográficas nos oferecem um flagrante de diversos momentos, mas é preciso procurar perceber a história ou as histórias que dão sentido àquelas imagens, captar traços das relações sociais que construíram a possibilidade de existência daquelas imagens. Elas nos incitam, portanto, a relacioná-las com rememorações de diversos sujeitos que vivenciaram, de alguma forma, a escola. Relatos que puderam ser obtidos conferem maior inteligibilidade e, sobretudo, maior densidade às imagens fotográficas.

Em encontro com uma antiga funcionária na escola, ali desde meados da década de 1980, presenciamos a manifestação de um sentimento nostálgico em relação aos primeiros tempos. Entrou como cozinheira do pré-escolar e acumulava a função de auxiliar das professoras. "Tomava conta do prezinho" e ajudava em muitas atividades: ensaiava festa junina, por exemplo, e quando alguma professora faltava, "deixava a comida no fogo e ia para a classe"; propunha desenhos para as crianças e várias cantigas. Algumas vezes faltavam ingredientes para a merenda das crianças e, então, "trazia fubá, couve de casa" para preparar uma sopinha. Referindo-se à terceirização de funcionários da limpeza, manutenção e cozinha e às modificações havidas nas relações de trabalho com o passar do tempo, declara com certa ênfase: "era tudo unido, uma união muito bonita". Rememora a atuação de vários personagens que, segundo ela, marcaram muito os primeiros anos da escola. Destaca a participação ativa de muitas mães e pais que colaboravam de várias maneiras para que a escola pudesse ter mais recursos e condições de apresentar um ensino melhor para seus filhos. Relembra a existência de uma Comissão de Pais que ajudou a construir as salas da pré-escola; relembra também a atuação dinâmica de vários professores que, além das próprias aulas, se envolviam muitas vezes na faxina das salas e nos consertos necessários.

A colaboração e a participação coletiva se revela uma tônica bastante forte tanto na rememoração desta funcionária quanto nas rememorações de um grupo de pessoas que se reuniu numa tarde de sábado para narrar suas memórias de momentos que julgavam significativos da história da escola. Estiveram presentes alguns professores e ex-professores, funcionários e exfuncionários e uma ex-aluna. Era possível perceber certa carga emocional, afetiva e sensível nos presentes naquela tarde.

Cenas e cenários diversos trazidos à tona foram compartilhados em meio a alguns breves comentários melancólicos sobre certo esvaziamento, certo esgarçamento que se observa, mais atualmente, nas relações da escola com a comunidade do entorno. No entanto, como frisou uma mãe, que teve os filhos na escola durante toda a década de 1990, havia muita participação das mães, era "uma época muito boa que não vou esquecer", uma época da qual sente bastante saudade. Uma exprofessora confessa que "valeu a pena ter trabalhado aqui"; ressalta que havia uma "parceria muito grande entre direção, funcionários e colegas"; relembra dos pais participativos que lotavam as reuniões da Associação de Pais e Mestres (APM), e que cobravam bastante da escola um padrão de qualidade de ensino. Com entusiasmo, reafirma que havia "muita amizade, companheirismo".

Outro ex-professor se lembra "da rua de terra, dos terrenos vazios" e comenta das mudanças do espaço físico da escola e do entorno. "Era minha escola do coração", confessa.

Festas organizadas para angariar fundos para garantir melhorias para a escola são relembradas por muitos dos presentes. A "comunidade era muito aberta para a participação. Pais e professores muito animados trabalhavam até nos finais de semana", relata uma ex-diretora. Muitas feijoadas foram feitas na escola aos sábados para conseguir recursos. "Até os alunos ajudavam". De batedeira para a cozinha, mimeógrafo, bebedouro a "máquina de xerox", muitas necessidades foram supridas com apoio da mobilização das famílias que se organizavam para determinadas finalidades. Dessa forma, muitos voluntários se dispunham a arrecadar jornal nas vizinhanças para vender, diversas mães se 
dedicavam a fazer pastéis ou cachorro-quente, muitos contribuíam para organizar as tradicionais festas juninas. Havia algumas mães feirantes que cediam alimentos para a merenda dos alunos.

Terminar a quadra de esportes e colocá-la em boas condições de uso, inclusive no que diz respeito às laterais e ao acesso - a Prefeitura teria contribuído apenas com uma parte dessa construção -, também foi resultado do empenho de muitos pais que se mobilizavam para conseguir material e vir aos sábados para trabalhar. "São tantas lembranças", dizia um dos presentes.

Um professor se refere à grande preocupação com a cultura, não apenas com o "conteúdo programático" tradicional. "Saía muito com os alunos", conta, e muitas vezes os levava de "ônibus de linha" até a Biblioteca Municipal para ver exposição de artes. Uma ex-professora relata que "ia muito para o Museu do Ipiranga" e também gostava de levar os alunos para a Leco, empresa de laticínios em Campinas. Outra professora se recorda de que foram também de ônibus urbano ao centro da cidade, em frente à Catedral, "para assistirem um teatro de rua". Um dos professores, que se mantém há muito tempo na escola, ressalta a continuidade de trabalhos com saraus e de propostas de saídas para diversos lugares da cidade. E enfatiza, com relação ao trabalho educacional, que tem sido importante "ampliar, ir além dos conteúdos programáticos", postura que tem se configurado como uma "marca forte desta escola".

As memórias que foram desfiadas trouxeram à tona a atuação de diferentes sujeitos que ultrapassaram os entraves de seu cotidiano para dar vida e garantir a existência de uma escola em melhores condições para seus filhos e/ou alunos. No entanto, parece-nos que trouxeram algo mais a ser melhor compreendido. A articulação entre as fotografias que compuseram a exposição "Fragmentos de uma história" e esse conjunto de breves rememorações produziu uma teia de sentidos que se desdobram em diversas possibilidades reflexivas.

Em vários momentos da existência dessa instituição escolar houve olhares e posturas sensíveis ao coletivo, ao compartilhamento. Uma rede de relações solidárias emerge nos relatos, em especial ao longo dos primeiros vinte anos da escola. Emerge, sobretudo, uma vontade e um empenho manifesto em superar as dificuldades impostas por precariedades diversas presentes numa escola pública municipal. Foi possível reconhecer práticas pedagógicas que parecem entender a educação de crianças e adolescentes mais como um processo de formação de condições para uma leitura aberta do mundo do que como apenas um processo de reprodução eficiente de conteúdos ensinados de forma expositiva. Abertura às parcerias com grupos ligados às artes e também à assessoria para a introdução de novas tecnologias ampliaram, certamente, os horizontes dos alunos que vivenciaram essas situações.

Estamos diante, de fato, de fragmentos de uma história. Todavia, arriscamos dizer que são fragmentos incômodos, que não se restringem a um recolhimento silencioso em momentos passados, mas lançam problematizações e questionamentos ao nosso presente.

\section{A explicitação de um patrimônio cultural}

Queremos sugerir que os fios dessas memórias apontam para a existência de um patrimônio cultural com a potencialidade de ressignificar os sentidos atribuídos à trajetória da escola por vários de seus participantes.

Mas, como pensar a questão de um patrimônio cultural em constante formação numa escola pública? E, consequentemente, como pensar possibilidades de uma educação patrimonial? Acreditamos tratar-se de um desafio que vale a pena ser enfrentado.

Pensamos ser de fundamental importância que a comunidade escolar seja sensibilizada a perceber e a reconhecer a existência de um patrimônio, de natureza coletiva, que vai muito além dos edifícios, mobiliário e equipamentos diversos existentes na instituição. Um patrimônio constituído por um complexo de relações fundadas, por um lado, no conjunto de documentos oficiais que possui e nos diferentes registros textuais e iconográficos de suas atividades e, por outro lado, no conjunto difuso, mas não menos importante, das memórias inscritas em suas paredes, em seus diferentes espaços, e trazidas à tona pelos relatos de sujeitos que participaram de diversos momentos da trajetória da história da escola. Uma forma de patrimônio em movimentação constante e que, de certo modo, está sujeito a seleções, escolhas e à atribuição de valores (POSSAMAI, 2012; PEREIRA, 2015). Um patrimônio constituído por memórias e histórias que se oferecem a formas possíveis e diversas de apropriação.

Temos assistido nos últimos anos e, talvez, nas últimas décadas, a uma preocupação 
significativa com as questões da memória e da preservação do patrimônio cultural (HUYSSEN, 2000; ORIÁ; PEREIRA, 2012). Atividades ligadas à educação patrimonial vêm sendo desenvolvidas por instituições culturais, historiadores, professores, preocupados com as questões da memória em suas várias dimensões e com as condições de sua preservação.

A ampliação da noção de patrimônio histórico para patrimônio cultural, indo além do patrimônio edificado, possibilitou incorporar "os registros e modos de expressar a cultura de diferentes grupos étnicos e sociais que contribuíram e contribuem para a formação da sociedade brasileira" (PEREIRA; ORIÁ, 2012, p. 166). O conceito de educação patrimonial, difundido em meados da década de 1980 a partir da atuação de Maria de Lourdes Horta no Museu Imperial de Petrópolis, localizava-se num contexto histórico de luta contra a destruição de bens e registros históricos nacionais (PEREIRA, 2012). Todavia, com as ressignificações havidas, os diversos sujeitos envolvidos com a questão do patrimônio têm difundido a concepção de patrimônio cultural como uma "construção histórica e seletiva da memória de uma dada comunidade, em suas dimensões sensíveis, éticas e políticas" (idem, p.165).

Nessa perspectiva, como ressalta Sandra Pelegrine em sua discussão sobre o patrimônio imaterial brasileiro na contemporaneidade, [...] a salvaguarda de um bem material ou imaterial só tem sentido se esse patrimônio for reconhecido pela comunidade, se estiver relacionado ao sentimento de pertença desse grupo e incluso na dinâmica sociocultural (2008, p. 150).

Num movimento de ampliação da abordagem das relações entre patrimônio e educação, é importante destacar a contribuição de Helenice Ciampi a esta questão:

Ressalto a importância de uma ação voltada para a percepção da pluralidade de histórias e memórias, heranças transmitidas como bens materiais e imateriais que formam o patrimônio cultural das diferentes comunidades. Tais elementos são fundamentais para a construção de nossas identidades e práticas que incorporam essas concepções e revelam profissionais comprometidos com uma educação patrimonial consequente e vinculada às questões contemporâneas (CIAMPI, 2015, p. 68).

As relações tecidas por essas autoras entre patrimônio e sentimento de pertencimento proporcionado ao grupo social que o acolhe e dele se apropria, entre patrimônio e identidade, são relações por demais pertinentes para as reflexões que propomos em torno da escola.

A sociedade contemporânea, por ser permeada pelos ritmos acelerados da modernidade $\mathrm{e}$ pela atmosfera da transitoriedade e do efêmero, tem produzido vínculos frágeis com os diversos lugares da cidade, bem como tem tornado essa fragilidade presente nas relações interpessoais. Estamos constantemente circulando e de passagem por diversos lugares (AUGÉ, 1994), sem garantir os intervalos necessários para o tempo da observação, da reflexão, da escuta, da partilha, da convivência.

Nesse contexto, podemos sugerir que crianças e adolescentes que crescem e vivem nesta sociedade tendem a ser educadas em suas sensibilidades pelas dinâmicas socioculturais predominantes. Tendem a não constituir para si referências espaciais e identitárias mais consistentes.

A Escola Prof. ${ }^{a}$ Dulce Bento Nascimento constitui-se, como outras instituições escolares, espaço de educação e de memórias. Memórias e histórias plurais, indiciando possibilidades educacionais também plurais (GALZERANI, 2002). Memórias e histórias que conferem uma movimentação à trajetória da escola ao longo dos anos. Uma história escolar não linear que tem se desenrolado entre continuidades e descontinuidades, atravessada pelas tensões e contradições provenientes das diferentes concepções e práticas dos diversos sujeitos protagonistas dessa história. $\mathrm{O}$ equilíbrio instável entre permanência e impermanência atravessa a história da escola enquanto instituição. E enquanto instituição ela apresenta uma tradição escolar que, no entanto, é constantemente submetida a oscilações vindas de novas práticas que se incorporam, de outras visões, de novos sujeitos que ali se estabelecem. Essa dinâmica da cultura escolar que ali se constituiu e se constitui dificulta e torna opaca a percepção de que aquele conjunto de histórias e memórias que constituem a trajetória da instituição escolar possa ser considerado um patrimônio, um patrimônio cultural. Patrimônio que, em suas lacunas e descontinuidades, merece ser olhado, sentido, redescoberto; patrimônio que possivelmente abriga possibilidades outras de atuação educacional que não foram tão desenvolvidas e que podem, talvez, oferecer possibilidades criativas significativas para o presente; patrimônio cultural em permanente constituição que, em sua incompletude, apresenta a 
potencialidade de sugerir aos participantes dessa trajetória que eles podem assumir sua condição de sujeitos participantes dessa história.

Ressaltamos, portanto, a importância da percepção da pluralidade de histórias e memórias no espaço da escola a fim de que tanto professores e funcionários quanto alunos tenham condições de ultrapassar sensações de desenraizamento do lugar. O sentimento de pertencimento se alimenta das vinculações culturais que construímos nos lugares em que vivemos. No caso da escola em questão, as memórias imbricadas nas histórias da instituição oferecem a potencialidade de construção das identidades de grupos sociais ali presentes e a possibilidade de formação de certa consciência histórica (NEVES; MARTINS, 2008). Sentir-se vinculado à história, partilhar das memórias, permite um caminho para o sentir-se sujeito participante de algo, um sujeito de rosto mais definido que drible uma sensação de anonimato generalizado.

No entanto, há que não se desconsiderar necessidades de escolhas e posicionamentos. Sem nos deixar envolver por visões ingênuas, é imperioso reconhecer a importância do alerta de Fátima Guimarães: "[...] ao tratar de patrimônio cultural (material e imaterial), atento para a existência de memórias e histórias plurais, de relações de poder imbricadas em apagamentos e silenciamentos produzidos por diferentes práticas socioculturais (2015, p. 92).

As dinâmicas socioculturais da contemporaneidade nos induzem a esquecimentos, ao descarte. Relações de poder que prevaleçam no interior de instituições também concorrem para determinados esquecimentos e silenciamentos.

$\mathrm{O}$ conjunto de situações e atividades trazidos à tona por imagens que fizeram parte da exposição teriam encontrado ressonância entre os envolvidos nos processos educativos da escola (GONÇALVES, 2005)? Que apropriações os diferentes sujeitos - como professores, alunos e funcionários - possam ter feito e estar fazendo do material que foi exposto e divulgado de seu patrimônio?

Processos educacionais podem ser ativados e desenvolvidos no sentido da educação de outras formas de sensibilidades para com um patrimônio cultural em constante movimentação. A partir do conhecimento e reconhecimento do patrimônio cultural escolar a comunidade escolar - professores, alunos, funcionários - tem a possibilidade de se reconhecer como parte ativa, como sujeito de sua história, motivando-se a preservar bens culturais como parte da constituição de sua identidade. Um processo de valorização de seus bens culturais, que propicie a autoestima dos segmentos sociais envolvidos, condição imprescindível para a autoconsciência, inclusive, de cidadania, do cuidado com o outro, com o espaço público, com o interesse coletivo.

A exposição nos trouxe, portanto, fragmentos do passado na relação com o presente. Importa pensar, sobretudo, quais acenos para o nosso presente esses fragmentos nos fazem. Que convites estão, silenciosamente, à espera de escuta? Quais sugestões de continuidade em nosso presente?

\section{Notas}

1 Este projeto de extensão foi realizado com o apoio do $8^{\circ}$ Edital PREAC PEC 2014, programa da Pro Reitoria de Extensão e Assuntos Comunitários da Universidade Estadual de Campinas, para o período 2014-2015. Contou com a coordenação da pesquisadora Maria Elena Bernardes e com os seguintes participantes do CMU: Cássia Denise Gonçalves, Marli Marcondes, Ricardo Godoi de Oliveira e a pesquisadora Maria Silvia Duarte Hadler. Pela Escola Professora Dulce Bento Nascimento participaram os professores Cláudio Borges da Silva, Edna Andrade Guevara Prado, Marcos Zacarias Farhat Junior, Marcos Alexandre Neves Guimarães, Silvia Helena Freitas e a orientadora pedagógica Aimar Shimabukuro e com o apoio institucional da diretora Priscila Maria Farah.

2 Esta Exposição contou com a participação fundamental de Claudio Borges e Marli Marcondes, que atuaram no trabalho de seleção e tratamento das imagens fotográficas, bem como no processo de organização desta Exposição.

\section{Referências}

AUGÉ, M. Não-lugares: introdução a uma antropologia da supermodernidade. Campinas, SP: Papirus, 1994.

BENJAMIN, W. Obras escolhidas I. Magia e técnica, arte e política: ensaios sobre literatura e história da cultura. Tradução de Sérgio P. Rouanet. São Paulo: Brasiliense, 1985.

CIAMPI, H. Mediações entre Ensino de História e Patrimônio. In: ZAMBONI, E.; GALZERANI, M. C. 
B.; PACIEVITCH, C. (Orgs.). Memória, sensibilidades e saberes. Campinas, SP: Alínea, 2015, p. 64-75.

GALZERANI, M. C. B. Imagens entrecruzadas de infância e de produção de conhecimento histórico em Walter Benjamin. In: FARIA, A. L. G.; DEMARTINI, Z. de V. F.; PRADO, P. D. (Orgs.). Por uma cultura da infância. Campinas: Autores Associados, 2002.

GALZERANI, M. C. B. O lugar das memórias na produção dos saberes escolares. In: BEZERRA, H.; LUCA, T. de (Orgs.). O historiador e seu tempo. ANPUH(SP) - XVIII Encontro Regional de História. São Paulo, 2007.

GONÇALVES, J. R. Ressonâncias, materialidade e subjetividade: as culturas como patrimônios. Horizontes Antropológicos, Porto Alegre, ano 11, n. 23, p. 15-36, jan/jun 2005.

GONÇALVES, J. R. S. O patrimônio como categoria de pensamento. In: ABREU, R.; CHAGAS, M. (Orgs.). Memória e patrimônio: ensaios contemporâneos. Rio de Janeiro: DP\&A Edit., 2003.

GUIMARÃES, M. F. Patrimônio Cultural e ensino de História: problematizando a colonização do presente pelo passado. In: ZAMBONI, E.; GALZERANI, M. C. B.; PACIEVITCH, C. (Orgs.). Memória, sensibilidades e saberes. Campinas - SP: Alínea, 2015. p. 90-102.
HUYSSEN, A. Seduzidos pela memória: arquitetura, monumentos, mídia. Rio de Janeiro:Aeroplano, 2000.

MONGIN, O. A condição urbana: a cidade na era da globalização. São Paulo: Estação Liberdade, 2009.

NEVES, R. X.; MARTINS, M. C. Fontes escolares e a formação da memória educacional. In: ZAMBONI, E. [et al.]. Memórias e histórias da escola. Campinas - SP: Mercado de Letras, 2008.

PELEGRINE, S.; FUNARI, P. P. O que é patrimônio cultural imaterial? SP: Brasiliense, 2008.

PEREIRA, J. S. Ensino de História e Patrimônio na relação museu-escola. In: ZAMBONI, E.; GALZERANI, M.C.B.; PACIEVITCH, C. (Orgs.). Memória, sensibilidades e saberes. Campinas, SP: Alínea, 2015, p. 76-89.

PEREIRA, J.S.; ORIÁ, R. Desafios teóricometodológicos da relação Educação e Patrimônio. Resgate, revista interdisciplinar de cultura, v. XX, n. 23, jan/jun 2012, p. 161-171.

POSSAMAI, Z. R. Patrimônio e História da Educação: aproximações e possibilidades de pesquisa. Revista de História da Educação, v. 16, n. 36, jan/abr 2012, p. 110-120.

SENNET, R. Carne e pedra. Rio de Janeiro: Record, 1997.

\section{Sobre as autoras}

Maria Sílvia Duarte Hadler é Doutora em Educação pela da Faculdade de Educação da Universidade Estadual de Campinas. É pesquisadora do Centro de Memória-Unicamp, onde desenvolveu seu projeto de pós-doutorado. Mestre em Ciência Política, bacharel e licenciada em Ciências Sociais no IFCH da Universidade Estadual de Campinas.

Maria Elena Bernardes é pesquisadora (aposentada) do Centro de Memória-Unicamp. Doutora em História e mestre em História pelo IFCH da Universidade Estadual de Campinas.

Recebido em dezembro de 2016.

Aprovado em março de 2017. 